\title{
ESTRATEGIAS DE UN TRADUCTOR ESPECIALIZADO EN LA TRADUCCIÓN DE UN FRAGMENTO LITERARIO
}

\section{STRATEGIES OF A TRANSLATOR SPECIALIZED IN THE TRANSLATION OF A LITERARY FRAGMENT}

\author{
ESTRATÉGIAS DE UM TRADUTOR ESPECIALIZADO NA TRADUÇÃO DE UM FRAGMENTO LITERÁRIO
}

Laís de Sousa Nóbrega ${ }^{1}$

Idelso Espinosa Taset $^{2}$

1. Mestranda em Linguagem e Ensino (PPGLE-UFCG). Especialista em Ensino de Língua Espanhola e em Tradução. Licenciada em Letras - Espanhol. Contato: nobregalaisdesousa@gmail.com.

2. Doutor em Linguística Aplicada ao Ensino do Espanhol como Língua Estrangeira. Especialista em Tradução Português-Espanhol. Mestre em Linguística Aplicada. Graduação em Língua e Cultura Espanholas. Professor Efetivo no Curso de Licenciatura Espanhol da UFCG. Contato: etileitura@gmail.com.

Resumen: Esta investigación tuvo por objetivo identificar, describir y analizar los procedimientos técnicos utilizados por el traductor para solucionar los problemas que enfrentó en el acto traductorio. Para ello hemos escogido aleatoriamente un fragmento de la segunda parte de la obra Memoria de mis putas tristes, de Gabriel García Márquez. La fundamentación teórica está integrada por los conceptos de traducción profesional (MAYORAL, 2001; STUPIELLO, 2006); traducción literaria (CASTILLO, 2016; CATENARO, 2008); competencia traductora (ESPINOSA, 2011); y procedimientos técnicos de la traducción (BARBOSA, 2004). El corpus está integrado por un fragmento de la referida obra literaria, lo cual fue analizado atendiendo a la propuesta de categorización y jerarquización de Barbosa (2004). Los resultados mostraron un uso abrumador (80\%) de los procedimientos catalogados dentro de la traducción oblicua (incremento, equivalencia, modulación, omisión) y solo un $(20 \%)$ dentro de la traducción directa (traducción palabra por palabra y traducción literal). Los datos permitieron comprobar que el traductor encontró más divergencia que convergencia de los sistemas lingüísticos y de los estilos entre el par de lenguas en contacto, lo que parece explicar el recurso mayoritario a procedimientos que normalmente se aplicarían en la traducción literaria en esa magnitud.

Palabras-clave: Memoria de mis putas tristes. Competencia traductora. Procedimientos técnicos. Traducción literaria.
Abstract: This research aimed to identify, to describe and to analyze the technical procedures used by the translator in order to solve the problems faced during the translation act. In this case, it was randomly chosen a fragment of the second part from the novel Memoria de mis putas tristes, by Gabriel Garcia Marquez. The theoretical framework is based on the concepts of professional translation (MAYORAL, 1994; STUPIELLO, 2006); literary translation (CASTILlO, 2016; CATENARO, 2008); translation competence (ESPINOSA, 2011); and technical translation procedures (BARBOSA, 2004). The corpus consists on a fragment from the mentioned literary workwhich was analyzed considering the categorization and hierarchization purpose according to Barbosa (2004). The results showed an intensive use $(80 \%)$ of the procedures listed within the oblique translation (increment, equivalence, modulation, omission) and only (20\%) within the direct translation (word by word translation and literal translation). The data allowed to prove that the translator have found more divergence than convergence of the linguistic systems and the styles between the pair of languages in contact, and this explain the majority expedient to procedures which would be normally applied to the literary translation in this magnitude.

Keywords: Memoria de mis putas tristes. Translation competence. Technical procedures. Literary Translation.
Resumo: Essa pesquisa tem como objetivo identificar, descrever e analisar os procedimentos técnicos utilizados pelo tradutor para solucionar os problemas encontrados no ato tradutório. Para isso, escolhemos aleatoriamente um fragmento da segunda parte da obra Memoria de mis putas tristes, por Gabriel García Márquez. A fundamentação teórica está integrada pelos conceitos de tradução profissional (MAYORAL, 2001; STUPIELLO, 2006); tradução literária (CASTILLO, 2008; CATENARO, 2008); competência tradutória (ESPINOSA, 2011); e procedimentos técnicos da tradução (BARBOSA, 2004). O corpus está integrado por um fragmento da referida obra literária, o qual foi analisado considerando a proposta de categorização e hierarquização de Barbosa (2004). Os resultados mostraram um uso acentuado $(80 \%)$ dos procedimentos catalogados dentro da tradução oblíqua (incremento, equivalência, modulação, omissão) e somente (20\%) dentro da tradução direta (tradução palavra por palavra e tradução literal). Os dados permitiram comprovar que o tradutor encontrou mais divergência que convergência entre os sistemas linguísticos e os estilos entre o par de línguas em contato, o que parece explicar o recurso majoritário de procedimentos que normalmente se aplicariam nessa magnitude a tradução literária.

Palavras-chave: Memoria de mis putas tristes. Competência tradutória. Procedimentos técnicos. Tradução literária. 


\section{Introducción}

Este trabajo está situado en el ámbito de la lingüística aplicada, especificamente los Estudios de la Traducción como proceso y como producto. Básicamente sigue dos ejes temáticos: los procedimientos técnicos de traducción y la traducción literaria y se propone identificar, describir y analizar los procedimientos más recurrentes en la traducción de un fragmento de "Memoria de mis putas tristes", de Gabriel García Márquez, al portugués brasileño (PB).

La traducción es un conocimiento procesual, una habilidad que consiste en mediar dos culturas distintas, es la destreza de comprender e interpretar un texto en dos lenguas diferentes y tener la capacidad de producir un nuevo texto en otra comunidad lingüística/cultural. Por lo tanto, traducir nos remite a una tarea compleja y variable. Cuando se traduce un texto a otra lengua necesariamente estamos sembrando culturas y cuanto más se acerque el texto a la sensibilidad, a los sentimientos y a la subjetividad, más formas habrá de traducir. Así que, cuando el traductor va a traducir lo primero que tiene que conocer es (i) la naturaleza del texto (una vez que cada género textual posee unos fenómenos que mantienen unas finalidades específicas y unas características propias que pueden cambiar de una cultura a la otra), (ii) los objetivos del autor (consecuentemente del traductor) y (iii) el destinatario del texto original y del texto de la lengua traducida (NIDA, 1964, 1966 apud MOYA, 2004). Además, es importante que el traductor conozca los procedimientos técnicos, pues éstos, a pesar de no garantizarle la aceptabilidad de la traducción, le permitirán usarlos deliberadamente (MOYA, 2004).

Por esa razón, cabe decir que los procedimientos técnicos son herramientas facilitadoras que auxilian el traductor a lo largo del acto traductorio, y que la traducción literaria se distingue de las demás (la científico-técnica, la jurada...) entre otros aspectos, por pertenecer a un dominio discursivo que abarca géneros textuales/discursivos muy propios en los que la subjetividad del traductor gana destaque.

Como ya se dijo arriba, el objetivo general de nuestro trabajo es identificar, describir y analizar los procedimientos más recurrentes utilizados en la traducción de un fragmento de Memorias de mis putas tristes obra traducida al portugués brasileño, realizando el contraste de las dos lenguas/culturas de modo que se obtenga de manera interpretativa nociónes posibles de las dificultades que encontró el traductor en el proceso de traducción y las soluciones por las que optó. Eso nos confirma que toda traducción exige necesariamente una reflexión sobre la cuestión de la diferencia, de la semejanza y del poder, y por lo tanto, también se orienta por procedimientos traductorios que ayudan al traductor a desarrollar su trabajo con calidad y eficacia.

El interés por ese tema se originó a causa de la necesidad y curiosidad en investigar cuáles son los procedimientos que sigue un traductor, bien como, las dificultades que encuentra al momento de traducir, 
puesto que la traducción no se caracteriza por el intercambio de signos lingüísticos aislados, sino por la función comunicativa de un texto y es durante el acto traductológico que se expande consecuentemente la responsabilidad y autoridad del traductor. De esta manera, la elección de estrategias y procedimientos de traducción de un texto se vuelve un proceso creativo y variable.

El presente trabajo está dividido en tres partes. Inicialmente presentaremos el marco teórico que está organizado en: 1) conceptos de la traducción profesional (MAYORAL, 2001; STUPIELLO, 2006); 2) traducción literaria (CASTILLO, 2016; CATENARO, 2008); 3) perfil del traductor profesional y la competencia traductora (ESPINOSA, 2011); 4) procedimientos técnicos de la traducción (BARBOSA, 2004). Enseguida es la metodología. Por último, la presentación y análisis del fragmento elegido en la lengua original y con su traducción.

\section{Marco Teórico}

De acuerdo con Cordeiro (2004), varios autores contemporáneos brasileños (AUBERT, 1993; AZENHA JÚNIOR, 1999; RODRIGUES, 2000) y extranjeros (BASSNETT, 1981; NEWMARK, 1988; BAKER, 1992; ROBINSON, 2002; JIANG, 2002; VENUTTI, 2002) definen traducción como una transcodificación lingüística y cultural, que según Rodrígues (2000), exige necesariamente una reflexión sobre la cuestión de la diferencia, de la semejanza y del poder. Luego, la traducción no se caracteriza por el intercambio de signos lingüísticos aislados, sino por la función comunicativa de un texto. En ese sentido Aubert (1993, p.44) alerta que "una de las dificultades de traducción será, encontrar en la lengua de llegada, medios de expresión para un referente diverso de aquél que el complejo lengua/cultura de llegada usualmente expresa".

Pero lo que interesa en este trabajo es definir lo que es traducción profesional, sus características fundamentales y, a partir de aquí, establecer los rasgos distintivos de la traducción literaria, trazar el perfil del traductor profesional y describir la competencia traductora y el concepto de procedimientos técnicos de traducción. Es lo que intentamos hacer en los párrafos siguientes para luego ofrecer una visión de las investigaciones en torno de los procedimientos técnicos más utilizados en la traducción de textos literarios del español al portugués brasileño.

\section{Conceptos de la traducción profesional}

De acuerdo con la bibliografía consultada, no parece haber una definición única, precisa y aceptada universalmente de lo que se entiende por traducción profesional; sin embargo, según Mayoral (2001) ésta 
es la que realizan traductores profesionales, pagan clientes, forma parte de los procesos comunicativos reales y tiene un rasgo elevado de calidad.

Considerando lo que el referido autor apunta, comprendemos que no es una traducción gratuita, tiene el fin de comunicar y presenta una exigencia mayor en lo que se refiere a calidad. Para concretarla, es necesario que el traductor actúe como un mediador entre dos comunidades lingüístico-culturales distintas, que su trabajo sea de buena calidad y que posibilite a su cliente comprender lo traducido de una manera satisfactoria, sin que encuentre dificultades o le provoque extrañeza cuando vaya a leer.

Desde la perspectiva del escritor posmodernista Stupiello (2006) la traducción es una producción y no una reproducción de significados, reflexionando sobre la imposibilidad de transferencia de significados intactos. Por lo tanto, podemos inferir que la traducción supone entender, comprender e interpretar el texto original recreándolo en una lengua/cultura diferente.

\section{Traducción Literaria}

La traducción de textos literarios escritos trae consigo una gran responsabilidad, puesto que el traductor deberá ingeniársela para mantener el significado del texto original; preservar la forma, el estilo y la voz del autor y producir un texto adecuado a la índole de la lengua del texto de llegada y la realidad cultural de sus lectores. Requiere del traductor un alto nivel de creatividad y recursividad, así como de excelentes habilidades de escritura.

En este mismo sentido, para Catenaro (2008) la traducción literaria ha de considerar un conjunto de elementos sentimentales, emocionales, sensuales, críticos, dentro de una estructura verbal sostenida por una cultura determinada.

Así podemos decir que la traducción literaria tiene algunas peculiaridades que la hacen diferente de los otros tipos de traducciones.

De acuerdo con Castillo (2016), algunas de las características de la traducción literaria son: (i) la originalidad de estilo; (ii) el intento de comunicar lo abstracto y lo inefable; (iii) la creación de una realidad no vivida; (iv) la invención de hechos y situaciones; (v) el uso de jerga para crear un ambiente, acentos y personajes; (vi) la utilización de modismos y recursos exóticos; (vi) la realización de rodeos, descripciones extensas, exclamaciones; (vii) la facilidad de modificar los puntos de vista según los personajes o emociones del autor; (viii) la posibilidad de mezclar hechos con opiniones;(ix) invitación a la introspección $\mathrm{y}$ al goce interior de imágenes, ideas y sensaciones; (x) la preferencia por lo arbitrario; (xi) la no obligatoriedad de seguir un orden especial; (xii) la posibilidad de violentar el concepto lineal de tiempo y espacio; y (xiii) la explicación queda en manos del lector. 


\section{El perfil del traductor profesional}

De las características de la traducción profesional general y de los rasgos distintivos de la traducción literaria se desprende que este acto de mediación comunicativa supone que el perfil del traductor está integrado por un conjunto de conocimientos y habilidades específicos.

Para Schäffner y Adab (2000 apud ESPINOSA, 2011), la competencia traductora (CT) está integrada por varias subcompetencias interrelacionadas (lingüística, cultural, textual, de asunto y de transferencia). Para esas autoras, esa definición es esencial para que se pueda intentar identificar los principios teóricos que servirían de base sólida al diseño de programas realistas que garanticen la adquisición y el desarrollo de los conocimientos y habilidades necesarios al traductor.

En este sentido, Espinosa (2011) comenta que Pym (2008, p. 22 apud ESPINOSA, 2011, p.17) enfatiza que "no hay ninguna definición clara de todas las cosas que los traductores necesitan saber ni de aquéllas para las cuales serán llamados a hacer"; eso nos hace inferir que traducir es un trabajo arduo, exige del traductor bastante tiempo, dedicación, conocimientos, técnicas y habilidades para que sepa identificar el nivel de complejidad del texto y haga uso de los procedimientos técnicos adecuados con el fin de alcanzar su objetivo final que es lograr comunicarse en otra cultura.

En el estudio de Espinosa se observa que el PACTE (2001, p.39-42 apud ESPINOSA, 2011, p.1920) parte de los supuestos de que la CT (i) es un sistema subyacente de conocimientos, habilidades y aptitudes necesarias para traducir; (ii) es cualitativamente distinta de la competencia bilingüe; (iii) como todo conocimiento especializado, posee componentes declarativos y operativos, aunque sea un conocimiento básicamente operativo y (iv) está formada por un conjunto de subcompetencias en la cual existen relaciones, jerárquicas y variaciones. Las seis subcompetencias de la CT descriptas por Pacte (2001 apud ESPINOSA, 2011) son semejantes a las que propone Hurtado (1996) y funcionan de manera imbricada para constituir la CT.

Por lo tanto, de acuerdo con (ESPINOSA, 2011, p.19), la CT estaría integrada por la competencia (i) comunicativa en las dos lenguas (conocimientos y habilidades necesarios para la comunicación lingüística en la forma de comprensión en la lengua de partida (LP) y de producción en la de llegada (LL), (ii) la extralingüística (conocimientos acerca de la organización del mundo en general y de ámbitos particulares), (iii) la instrumental/profesional (conocimientos y habilidades relacionadas con el ejercicio de la traducción profesional), (iv) la de transferencia (capacidad de investigar el proceso de transferencia desde el texto original hasta la elaboración del texto final), (v) la estratégica (procedimientos individuales utilizados para resolver los problemas encontrados en el desarrollo del proceso traductorio) y (vi) la psicofisiológica (habilidad para aplicar de recursos psicomotores, cognitivos y actitudinales). 
En resumidas cuentas, la competencia traductora en términos muy básicos, consiste en un conjunto de conocimientos y habilidades que le entregan al traductor la capacidad de comprender e interpretar significados y sentidos en una lengua de partida (LP) y producir un nuevo texto con esos significados y sentidos en una lengua de llegada (LL), respetando el estilo de la lengua y la realidad lingüística y cultural de la lengua en cuestión.

En esta investigación se asume que el perfil del traductor profesional está integrado por una consistente competencia traductora en los moldes descritos por el Grupo Pacte (2001 apud ESPINOSA, 2011) y una sólida conducta profesional ética. Es un profesional responsable por transfigurar, reescribir un texto adaptándolo a otra realidad cultural, a otra lengua. Tiene la función de crear y recrear sentidos y significados respetando los límites de la otra lengua/cultura. Esa competencia se manifiesta en la solución de los múltiples problemas que supone el acto de traducir. Para ello el traductor recurre a lo que los estudiosos llaman "procedimientos técnicos de traducción”, un término que abordamos en las siguientes líneas.

\section{Procedimientos técnicos de traducción}

Según Barbosa (2004), el término "procedimiento técnico de traducción” fue acuñado por Vinay y Darbelnet (1958) quienes lo entienden como procesos que se utilizan al pasar de una lengua a otra, o sea, hacen referencia a una totalidad de procesos de transferencia lingüística que participan en el acto traductorio. En este sentido, tales procedimientos se fundamentan en tres planos lingüísticos: el léxico, el morfosintáctico y el semántico. Por lo tanto, podemos entenderlos como herramientas lingüísticas que facilitan el trabajo del traductor. Sin embargo, de acuerdo con Vázquez Ayora (1968, p.251 apud BARBOSA, 2004), consideran que solo la práctica metódica puede proporcionar al traductor el dominio de estos procedimientos con los cuales logrará seguridad, facilidad y rapidez.

Como resumen de su propuesta Barbosa (2004, p.100-101) categoriza los procedimientos en un orden que va de los más simples a los más complejos, de los que envuelven unidades menores para los que envuelven unidades mayores, y, primordialmente, en el orden de los que su intuición revela ser más usados (más frecuentes) para aquellos menos usados (menos frecuentes), aunque no haya encontrado en la literatura subsidios para comprobar esta frecuencia.

En su propuesta de categorización, intentó eliminar la dicotomía entre traducción libre y traducción literal. Distribuyó los procedimientos a lo largo de cuatro ejes, aquellos donde sería generada la necesidad de cada procedimiento a fin de preservar el sentido, que es lo que prioriza en su propuesta sin imponer una división rígida. 
Una vez descriptos los conceptos fundamentales que guiaron esta investigación, a continuación intentaremos establecer los avances de estudios anteriores sobre el tema que nos ocupa.

\section{Metodología}

Este estudio pretendía identificar, describir y analizar los procedimientos traductorios utilizados por el traductor en la obra Memoria de mis putas tristes traducida al portugués brasileño, intentando percibir cuales fueron los procedimientos más recurrentes sin hacer juicios a sus criterios de traducción, pues sabemos lo subjetivo que es la traducción literaria. Así, el corpus de los textos comparados (españolportugués) está integrado por un fragmento escogido aleatoriamente de la segunda parte de la obra.

Como parámetro para el análisis del fragmento nos apoyamos en el trabajo de Barbosa (2004) que busca eliminar inconsistencias detectadas en su estudio y sugiere una nueva categorización. Nuestra investigación toma como base metodológica y referencia esta nueva categorización por considerarla más clara y operativa que las propuestas por otros autores.

En su obra - Procedimentos Técnicos da Tradução -, Barbosa (2004) agrupa algunas de las reflexiones que considera pertinentes sobre los diferentes conceptos de traducción y del acto traductorio. Reúne perspectivas de diferentes teóricos como Vinay y Darbelnet, Nida, Catford, entre muchos otros. La profesora presenta su propuesta de caracterización de los procedimientos técnicos de traducción combinando los conceptos y definiciones, eliminando algunos de los procedimientos y adecuando las terminologías.

La otra posibilidad de categorización de los procedimientos técnicos de traducción que defiende Barbosa (2004, p.91) se relaciona con el grado de divergencia entre la LO y la LT. Utilizó como base a su propuesta de categorización la constatación hecha por Vinay y Darbelnet (1977, p.46-48 apud BARBOSA, 2004) de que: 1) la traducción directa es posible cuando hay un paralelismo estructural y paralelismo extralinguiístico entre la LO y la LT, y 2) los ejemplos más numerosos de traducción literal son encontrados ente lenguas de la misma familia y sobretodo de la misma cultura. Esas dos afirmaciones permiten concluir que una divergencia lingüística y extralingüística mínima, la cual la denomina “convergencia”, permitirá el uso más frecuente de la traducción literal como procedimiento de traducción, al paso que una divergencia mayor entre esos factores obligaría el traductor a buscar recursos traductorios más complejos.

Otro aspecto que sirve de base para su propuesta de categorización son las dificultades que se encuentran en el acto de transponer de una lengua para otra, tal como presentadas por Mounin (1963): 1) las diferencias de las realidades extralingüísticas que cercan los pueblos hablantes de las varias lenguas; 2) las diversas maneras como cada sistema lingüístico divide y analiza las experiencias de la realidad 
extralingüística; 3) las organizaciones diversas de los sistemas lingüísticos, sea al nivel morfológico o sintáctico; y 4) las divergencias estilísticas, que se pueden en su trabajo como diferencias de registro, de la probabilidad de ocurrencia de un enunciado y del grado de adecuación de un enunciado a una situación (cf. HYMES, 1979, p.22-23).

Así que, en la propuesta de categorización de Barbosa (2004, p.91-92) los procedimientos técnicos de la traducción se distribuyeron a lo largo de cuatro ejes: 1) convergencia del sistema linguístico, de la realidad extralingüística y del estilo; 2) divergencia del sistema lingüístico; 3) divergencia del estilo y 4) divergencia de la realidad extralingüística.

Esta investigación sobre los procedimientos técnicos de traducción en Memoria de mis putas tristes también habrá de comprobar hipótesis/criterios aplicados por esta autora para su propuesta de categorización. Es lo que intentaremos lograr en el análisis de un fragmento de esta obra literaria, que constituye el corpus de esta investigación y que abordamos a continuación.

\section{Presentación y análisis del fragmento}

La obra Memoria de mis putas tristes está organizada en cinco partes. Sin embargo, escogimos aleatoriamente un fragmento de la segunda parte para formar el corpus de esta investigación en busca de los procedimientos técnicos más frecuentes en esta traducción literaria. A continuación, presentaremos el fragmento escogido y el análisis en función de los objetivos que se proponía nuestro estudio.

\section{Parte 2:}

\section{Fragmento:}

"A la izquierda del escritorio mantengo siempre las cinco fojas de papel de hilo tamaño oficio para mi nota dominical, y el cuerno con polvo de carta que prefiero a la moderna almohadilla de papel secante. A la derecha están el calamaio y el palillero de balso liviano con la péndola de oro, pues todavía manuscribo con la letra romántica que me enseñó Florina de Dios para que no me hiciera a la caligrafía oficial de su esposo, que fue notario público y contador juramentado hasta su último aliento." (GARCÍA MÁRQUEZ, 2004, p. 36).

\section{Traducción:}

“Á esquerda da escrivaninha mantenho sempre as cinco folhas de papel de linho tamanho oficio para minha crônica dominical, e o chifre com pó que prefiro á moderna almofadinha de mata-borrão. Á direita estão o tinteiro e o porta-caneta de madeira de lei com a pena de bico de ouro, pois ainda escrevo 
com a letra romântica que me ensinou Florina de Dios para que eu não me desse á caligrafia oficial de seu esposo, que foi notário público e contador juramentado até seu último suspiro.” (GARCÍA MÁRQUEZ, 2005, p. 38-39).

En el segundo fragmento es notorio que, por haber convergencia máxima, el traductor pudo aplicar en algunas partes la traducción palabra por palabra, pero también optó por otros procedimientos para solucionar los problemas, veámoslos en la tabla abajo:

Tabla 1: Fragmento

\begin{tabular}{|c|c|c|}
\hline ESPAÑOL & PORTUGUÉS & PROCEDIMIENTOS \\
\hline $\begin{array}{l}\text { "[...] el cuerno con polvo de } \\
\text { carta que prefiero a la } \\
\text { moderna almohadilla de } \\
\text { papel secante". }\end{array}$ & $\begin{array}{l}\text { "[...] o chifre com pó que } \\
\text { prefiro á moderna } \\
\text { almofadinha de mata- } \\
\text { borrão". }\end{array}$ & Omisión \\
\hline $\begin{array}{l}\text { "[...] el palillero de balso } \\
\text { liviano con la péndola de oro } \\
{[\ldots] " \text {. }}\end{array}$ & $\begin{array}{l}\text { "[...] o porta-caneta de } \\
\text { madeira de lei com a pena } \\
\text { de bico de ouro }[. . .] " .\end{array}$ & $\begin{array}{c}\text { Equivalencia, Modulación } \\
\text { e incremento }\end{array}$ \\
\hline $\begin{array}{l}\text { "[...] todavía manuscribo } \\
{[\ldots] " .}\end{array}$ & "[...] ainda escrevo $[\ldots] "$ & Palabra por palabra \\
\hline $\begin{array}{l}\text { "[...] no me hiciera a la } \\
\text { caligrafía oficial }[\ldots] " .\end{array}$ & $\begin{array}{l}\text { "[...] não me desse á } \\
\text { caligrafia oficial }[\ldots] " .\end{array}$ & Traducción literal \\
\hline
\end{tabular}

Fuente: elaboración de la autora.

En este fragmento, identificamos varios procedimientos utilizados en la traducción que sirven para reforzar la idea de que por más que el español/portugués sean un par de lenguas próximas, tienen índoles y estilos diferentes. En relación a “[...] el cuerno con polvo de carta que prefiero a la moderna almohadilla de papel secante", la traducción al portugués “[...] o chifre com pó que prefiro á moderna almofadinha de mata-borrão", el traductor omitió el sintagma "la carta" cuando lo tradujo al portugués, supuestamente porque creyó que sería innecesario, desde nuestra concepción por haber reducido esa oración no afectó en nada el sentido.

En "[...] el palillero de balso liviano con la péndola de oro [...]" traducida al portugués como "[...] o porta-caneta de madeira de lei com a pena de bico de ouro [...]", el traductor primero tradujo "pallitero" por "porta-caneta" para garantizar el sentido más claro, puesto que el equivalente en portugués "paliteiro" significa "fabricante de palitos", "persona que vende palito" y "lugar donde se colocan los palitos", lo que hizo fue utilizar el procedimiento de equivalencia, sustituyendo el segmento de la LO por otro segmento de 
la LT que no lo traduce literalmente, pero que funciona de manera equivalente. Además, si el traductor fuera a traducir literalmente "balso liviano" significaría "madeira leviana" sería una madera suave, pero por el sentido en el TLO optó por traducir como "madeira de lei", que es justo una madera de buena calidad, fuerte y resistente, luego podemos percibir que mantuvo el sentido en el TLT. Aparte de eso, no tradujo literalmente la palabra "péndola" que significa "pluma de escribir" sino que optó por "pena” en portugués; pero incrementó "de bico". Sin embargo, parece que ocurre una pérdida de sentido, porque la péndola de oro", significa que la pluma es toda de oro, y no solo la punta. Por eso entendemos que el procedimiento utilizado aquí fue la modulación facultativa, que es un procedimiento útil para resolver problemas derivados de la diferencia del estilo de las lenguas, abordado por Vinay Y Darbelnet (1977), también defendido por Vázquez-Ayora (1977) y Newmark (1981, 1988). De acuerdo con Barbosa (2004) en su categorización los dos procedimientos utilizados (equivalencia y modulación) se encuadran en la divergencia del sistema lingüístico de las dos lenguas en cuestión.

En traducción "[...] todavía manuscribo [...]" a "[...] ainda escrevo [...]", optó por la palabra "escrevo", pero desde nuestro punto de vista no imprime el mismo sentido expresado en el texto de la lengua original, pues "manuscribo" implícitamente sabemos que es el acto de "escribir algo manualmente", mientras que "escribo" es genérico y no especifica si la acción se realiza en una máquina de escribir o en una computadora, dos elementos que aportan información acerca del contexto temporal, o sea, deja el sentido más abierto, más amplio, y al lector del texto traducido puede no quedarle claro que fue algo escrito a mano. Por lo tanto, es posible percibir que utilizó el procedimiento palabra por palabra, lo que provoca una pérdida de sentido que se hubiera logrado si hubiera hecho una modulación "escrevo a mão". Y por último "[...] no me hiciera a la caligrafía oficial [...]” al portugués “[...] não me desse á caligrafia oficial [...]" cambió el verbo "haber" por el verbo "dar", el tiempo verbal que en español estaba en "pretérito imperfecto de subjuntivo" y tradujo al "pretérito indefinido/pasado simple de indicativo" en portugués, o sea, se ajustó a la gramática de la lengua traducida utilizando el procedimiento de traducción literal por haber una convergencia en la LTO y en la LTT, hizo el traductor una alteración morfosintáctica necesaria para producir un texto aceptable en el PB, según Barbosa (2004), sea el segundo procedimiento más común en las traducciones.

A continuación presentaremos dos gráficos: el primero corresponde a la traducción directa con el porcentaje de los dos procedimientos más utilizados (traducción palabra por palabra y traducción literal) en la traducción del fragmento escogido. El segundo gráfico a su vez, presenta los procedimientos referentes a la traducción oblicua: "incremento; omisión; modulación; equivalencia". 
Gráfico 1: Traducción Directa palabra por palabra

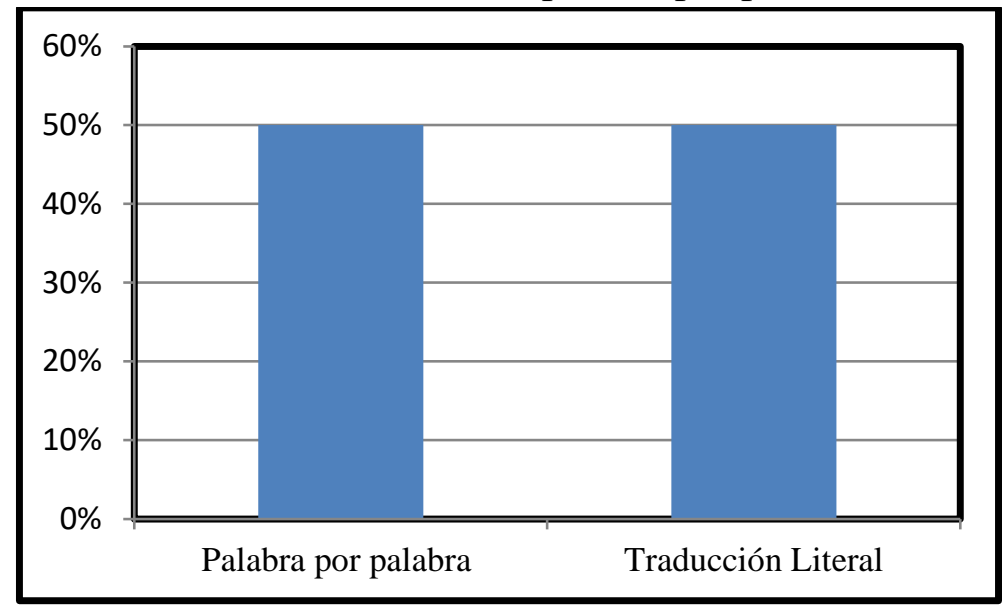

Gráfico 2: Traducción oblicua

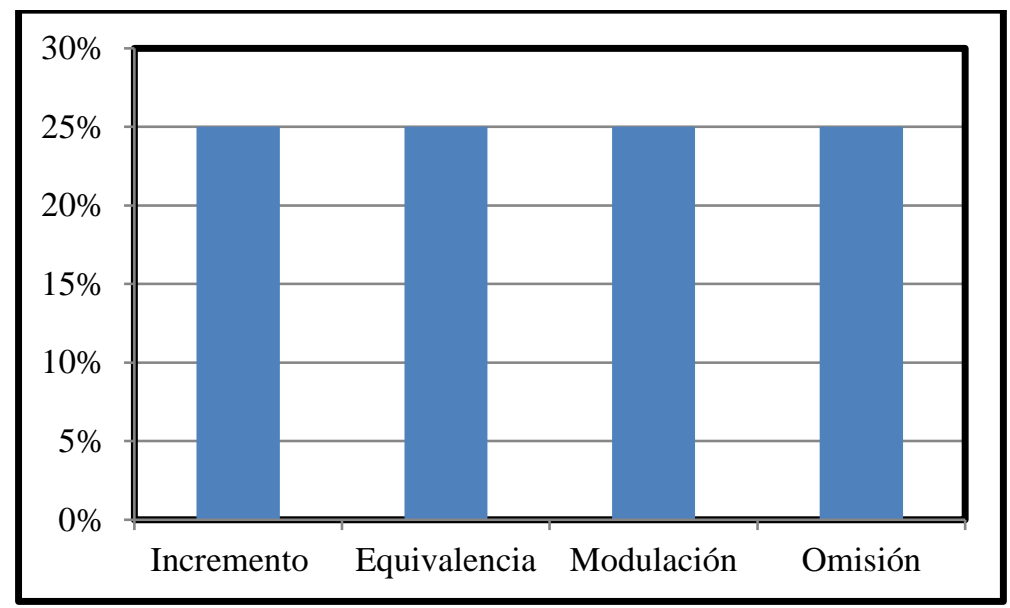

El gráfico dos nos presenta la síntesis de los procedimientos más complejos utilizados por el traductor que le sirvieron como herramientas para solucionar los problemas encontrados en el desarrollo del acto traductorio. Ante los resultados descritos arriba, entendemos que la categorización de Barbosa (2004) se basó en los estudios de Vinay y Darbelnet (1977), luego introdujo Nida (1964, 1966; NIDA; TABER, 1982), enseguida Catford (1965), después Vázquez-Ayora (1977) y finalizó en Newmark (1981;1988), y a través de ellos ordenó los procedimientos por un criterio progresivo de alejamiento de la LO y organizó su propuesta en cuatro ejes: 1) convergencia del sistema lingüístico, de la realidad extralingüística y del estilo; 2) divergencia del sistema lingüístico; 3) divergencia del estilo; y 4) divergencia de la realidad extralingüística.

En definitiva, por lo que hemos identificado en nuestro análisis, observamos que la equivalencia, la modulación y el incremento fueron utilizados una vez cada uno. Todos estos procedimientos se insertan en el eje dos. 
Dentro del eje tres (divergencia del estilo) se utilizó la omisión una vez. Por lo tanto, tenemos claro que los procedimientos técnicos de traducción reflejan las operaciones lingüísticas que el traductor realiza en una traducción (Barbosa, 2004, p. 107).

Gráfico 3: Tradución

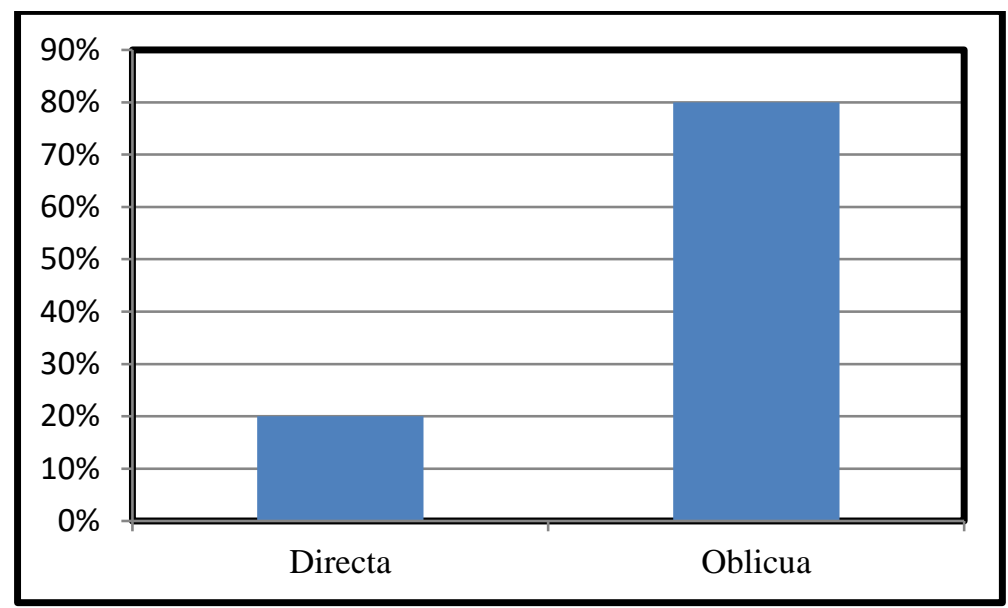

En el gráfico tres es posible que observemos que en la mayor parte de los fragmentos el traductor recurrió a procedimientos de la traducción oblicua (80\%) probablemente debido a la divergencia del sistema lingüístico, del estilo y de la realidad extralingüística. En contrapartida, la traducción directa obtuvo un espacio menor ocupando tan solo (20\%) ya este tipo de traducción se aplica, como ya hemos explicado, cuando el traductor encuentra convergencia de los sistemas lingüísticos en contacto, del estilo y de la realidad extralingüística.

Luego, podemos confirmar que por más que exista la cercanía del par lingüístico español-portugués, no siempre habrá convergencia. Como ya se dijo aquí, para Barbosa (2004) la convergencia entre las lenguas puede ser máxima o mínima; la primera es cuando el traductor puede hacer uso de la traducción palabra por palabra, o sea traduce al pie de la letra, mientras que en la segunda realiza alteraciones necesarias morfosintácticas para producir un texto aceptable en la LT. Ya cuando no hubo ningún tipo de convergencia, pero sí divergencia del sistema lingüístico y del estilo, el traductor tuvo que utilizar otros procedimientos técnicos de traducción para mantener el sentido del texto.

Los resultados del análisis confirman lo que presupone Barbosa (2004) sobre la frecuencia de uso de la traducción literal como procedimiento o estrategia en el acto traductorio. Aquí vale la pena recordar la constatación de Barbosa (2004, p.106) cuando escribe: "encontrei na literatura de (cf. Bordenave, 1987; Alves, 1983) subsídios para afirmar que, até hoje, não foi desvendado o mistério sobre o que se passa na cabeça do tradutor no ato da tradução". 
Y con este pensamiento reafirmamos la idea de que la traducción de textos literarios es altamente subjetiva, diferenciada, creativa y particular; y que todos los procedimientos sin restricción son igualmente válidos. Basta que el traductor los conozca y sepa usarlos de manera adecuada, y coherente cumpliendo el objetivo de producir un texto que sea aceptable en la lengua/cultura de llegada.

\section{Consideraciones Finales}

A través del estudio comparativo del fragmento de la obra literaria en español y el texto traducido fue posible identificar, describir y analizar los procedimientos técnicos que utilizó el traductor para solucionar los problemas encontrados en el proceso de traducción. Así, pudimos comprobar que aunque sean lenguas próximas se encontró más divergencia tanto en el sistema lingüístico como en el estilo y en la realidad. Tal vez esto explique el resultado que muestra una utilización más significativa de procedimientos técnicos que penden en la dirección de la llamada traducción libre u oblicua.

La otra consideración a que llevan los resultados de esta investigación es que diferentes procedimientos técnicos de traducción ya catalogados (y otros que puedan aparecer todavia) están presentes en mayor o menor grado en la traducción, incluso en la literária, como es el caso que nos ocupa. Esto parece tener relevancia para la didáctica de la traducción en el sentido de enseñar y aprender estrategias que si bien no garantizan la aceptabilidaad del texto traducido, si forman parte del conocimiento y dominio del traductor, pueden apoyarlo en su labor.

Sin embargo, consideramos una limitación del trabajo el hecho de haber analisado tan solo 1 fragmento debido al escaso tiempo disponible para realizar el necesario analisis profundo de las soluciones dadas por el traductor. En trabajos futuros pretendemos analizar más fragmentos o quizás toda la obra para que tengamos una mejor y más amplia visión de los procedimientos de traducción más frecuentes.

Esperamos que los resultados de esta investigación lleguen a contribuir modestamente con los estudios de traducción, específicamente a la traducción de textos literarios contemporáneos del par (español-portugués) que a nuestro modo de ver han sido poco estudiados.

\section{Referencias}

AUBERT, Francid Henrik. As (in)fidelidades da Tradução: Servidões e autonomia do tradutor. Campinas, SP: Editora da UNICAMP, 1993.

Disponible en: <https://es.scribd.com/doc/166160220/AUBERT-Francis-Henrik-As-in-fidelidades-datraducao-Servidoes-e-autonomia-do-tradutor>. Acceso en: 08 feb. 2016.

BARBOSA, Heloísa Gonçalves. Procedimentos técnicos da tradução: uma nova proposta. Campinas, SP: Pontes, 2004. 
CASTILLO, Irma Pereira. La traducción médica y la traducción literaria. Características, diferencias, ¿coincidencias? Departamento de Traducciones - XIII Simposio de Traducción Literaria, 2016. Disponible en: $\quad$ http://www.acti.cu/wp-content/uploads/2016/01/Ponencia-Traducci\%C3\%B3n-m\%C3\%A9dica-yliteraria.pdf $>$. Acceso en: 25 jul. 2016.

CATENARO, Barbara. La obra literaria: posibilidades y límites del traductor. Espéculo: Revista de Estudios Literarios, n. 37, p. 65, 2008. Disponible en:

<http://www.biblioteca.org.ar/libros/151712.pdf>. Acceso en: 25 jul. 2016.

ESPINOSA, Idelso Taset. As expectativas de alunos iniciantes de um curso de tradução espanholportuguês numa universidade federal a respeito da competência tradutória. Memória de Pósgraduação em tradução espanhol-português. Universidade Gama Filho, Rio de Janeiro, out. 2011.

GARCÍA MÁRQUEZ, Gabriel. Memoria de mis putas tristes. Barcelona: Editora Debosillo, 2004.

GARCÍA MÁRQUEZ, García. Memória de minhas putas tristes. Tradução de Eric Nepomuceno. $8^{\mathrm{a}}$ ed. Rio de Janeiro: Record, 2005.

MAYORAL, Roberto Asensio. Aspectos Epistemológicos de la Traducción. Universitat Jaume I, n.8, p.56, 2001. Disponible en: <https://books.google.com.br/books?isbn=8480213450>. Acceso en: 17 mayo 2016.

MOYA, Virgilio. "La selva de la traducción: teorías traductológicas contemporáneas". Madrid, Cátedra, 2004.

NÓBREGA, Laís de Sousa. Los procedimientos de traducción más recurrentes en cinco fragmentos de Memoria de mis putas tristes. Monografía (Trabajo de Conclusión de Curso: Licenciatura en Letras Español). Universidade Federal de Campina Grande, Campina Grande-PB, 2016.

STUPIELLO, Érika Nogueira de Andrade. O ideal e o real no ensino universitário da tradução. Cadernos de Tradução, v. 1, n. 17, p. 129-139, 2006. Disponible en: <https://periodicos.ufsc.br/index.php/traducao/article/view/6858/6410>. Acceso en: 09 feb. 2016. 